\title{
Seed priming with calcium chloride improves the photosynthesis performance of faba bean plants subjected to cadmium stress
}

\author{
I. NOUAIRI",+, K. JALALI*, F. ZRIBI**, F. BARHOUMI*, K. ZRIBI*, and H. MHADHBI* \\ Laboratory of Legumes, Centre of Biotechnology of Borj Cedria, B. P. 901, 2050 Hammam-Lif, Tunisia* \\ Laboratory of Extremophile Plants, Centre of Biotechnology of Borj Cedria, B. P. 901, 2050 Hammam-Lif, Tunisia**
}

\begin{abstract}
Faba bean (Vicia faba L.) seeds were treated with $\mathrm{H}_{2} \mathrm{O}$ [nonprimed (NP)] or $2 \% \mathrm{CaCl}_{2}$ [primed (P)] before germination for $6 \mathrm{~h}$. After seven days, seedlings were exposed to 0 or $50 \mu \mathrm{M} \mathrm{CdCl}_{2}$ concentrations for three weeks. Under Cd treatment, P plants showed an improvement of gas-exchange characteristics, chlorophyll (Chl) and carotenoids contents as compared to NP plants subjected to Cd stress. Additionally, the values of Chl fluorescence were relatively similar to those of control, implying that no photodamage occurred. Moreover, under $50 \mu \mathrm{M} \mathrm{Cd}$, the P plants exhibited lesser accumulation of hydrogen peroxide and superoxide radicals in leaves as compared to NP plants. Likewise, results showed that $\mathrm{CaCl}_{2}-$ seed pretreatment alleviated adverse effects of $\mathrm{Cd}$ on electrolyte leakage. In conclusion, $\mathrm{CaCl}_{2}$ improved photosynthesis attributes of faba bean plants subjected to Cd stress by mitigating the adverse effects of Cd toxicity through a reduced generation of reactive oxygen species.
\end{abstract}

Additional key words: nonphotochemical quenching; photosynthetic apparatus; seed priming; water-use efficiency.

\section{Introduction}

Cadmium pollution is increasing day by day due to industrialization and anthropogenic activities, such as traffic, smelting, and mining (Karadaş and Kara 2011). Similarly, excessive use of phosphate fertilizers is a major cause of the increase in Cd concentrations in soils (Qadir et al. 2000). The main symptoms of Cd-induced toxicity in plants are stunted growth, yellowing of leaves, damage to chloroplast ultrastructure, and ultimately plant death (Daud et al. 2009). Photosynthetic processes are directly affected by $\mathrm{Cd}$ ions, which disturb the carbon utilization and respiration mechanisms (Prasad 1995, Sanità di Toppi et al. 2003). Cd toxicity retards the photosynthetic rate by disturbing plant water balance, stomatal conductance, $\mathrm{CO}_{2}$ availability (Shi et al. 2010, Agami and Mohamed 2013), chloroplast organization (Miller et al. 2008, Najeeb et al. 2011), membrane structure integrity, and photosynthetic apparatus (Ekmekçi et al. 2008, Shi et al. 2010). This is due to the generation of reactive oxygen species (ROS), which deteriorate the physiological functions in plants (Dixit et al. 2001, Schützendübel et al. 2001). Many studies showed that $\mathrm{Cd}$ can increase the production of ROS, such as superoxide anion $\left(\mathrm{O}_{2}^{--}\right)$and hydrogen peroxide $\left(\mathrm{H}_{2} \mathrm{O}_{2}\right)$ (Prasad 1995, Schützendübel et al. 2001, Zhang et al. 2009). These ROS are able to react with lipids, proteins, and pigments, resulting in membrane damage and enzyme inactivation (Agami and Mohamed 2013).

Various physiological practices have been applied to alleviate the adverse effects of biotic and abiotic stress on normal plant functioning. Seed priming is one of the most effective and cost-efficient methods for seed quality improvement and stress tolerance in plants (Paparella et al. 2015). This technique is based on controlled seed hydration that induces a particular physiological state in plants (initial steps of germination sensu stricto). This process allows the application of natural and synthetic compounds into the seeds before their germination. Selection of some exogenous chemical priming such as calcium ions can regulate plant metabolism and improve plant resistance (Jiang et al. 2005, Delian et al. 2014). Calcium $\left(\mathrm{Ca}^{2+}\right)$ is involved in the regulation mechanisms that plants activate to adjust the adverse environmental conditions such as heavy metals (Antosiewicz and Hennig 2004, Siddiqui et al. 2011). Several authors have reported the alleviation of cadmium toxicity by $\mathrm{Ca}^{2+}$ in many plants, such as beans

\footnotetext{
Received 18 April 2018, accepted 14 November 2018.

${ }^{+}$Corresponding author; phone:(+216) 22572937, fax: (+216) 79325638, e-mail: issam.nouari@,cbbc.rnrt.tn

Abbreviations: $\mathrm{Car}$ - carotenoids; $\mathrm{Chl}$ - chlorophyll; $C_{\mathrm{i}}$ - internal $\mathrm{CO}_{2}$ concentration; $E$ - transpiration rate; EL - electrolyte leakage; ETR - photosynthetic electron transport rate; $F_{0}$ - minimal chlorophyll fluorescence; $F M$ - fresh mass; $F_{m}$ - maximal chlorophyll fluorescence; $\mathrm{F}_{\mathrm{m}}{ }^{\prime}$ - maximal fluorescence yield of the light-adapted state; $\mathrm{F}_{\mathrm{s}}$ - steady-state fluorescence yield; $\mathrm{F}_{\mathrm{v}}$ - variable chlorophyll fluorescence; $F_{\mathrm{v}} / F_{\mathrm{m}}$ - maximum photochemical quantum efficiency of PSII; $g_{\mathrm{s}}$ - stomatal conductance; NPQ - nonphotochemical quenching; $P_{\mathrm{N}}$ - net $\mathrm{CO}_{2}$ assimilation rate; ROS - reactive oxygen species; SE - standard error; WUE - intrinsic water-use efficiency $\left(P_{\mathrm{N}} / g_{\mathrm{s}}\right) ; \Phi_{\mathrm{PSII}}-$ actual PSII efficiency.

Acknowledgements: The authors are grateful for the financial support provided by the Tunisian Ministry of Higher Education and Scientific Research.
} 
(Ismail 2008), radish (Siddiqui et al. 2013), and cabbage (Chen et al. 2002).

Moreover, in a previous study, we found that seed priming with $\mathrm{CaCl}_{2}$ was effective in reducing the adverse effects of $\mathrm{Cd}$ on $V$. faba seedlings (Nouairi et al. 2012). Calcium appears to play a central role in many defense mechanisms that are induced by environmental stresses (Delian et al. 2014, Hironari and Takashi 2014), and $\mathrm{Ca}^{2+}$ signalling is required for the acquisition of plant tolerance (Delian et al. 2014).

The objective of the present study was to assess ameliorative roles of $\mathrm{CaCl}_{2}$-seed priming against the cadmium toxicity in faba bean plants based on the measurement of the photosynthetic parameters, ROS accumulation, and the electrolyte leakage (EL) in leaves.

\section{Materials and methods}

Plant growth and treatment: Seeds of faba bean (Vicia faba L. cv. Saber 02) were surface-sterilized for 3 to $4 \mathrm{~min}$ with $0.1 \% \mathrm{HgCl}_{2}$ and washed thrice with deionized water and then divided into two parts. For priming, one part was soaked in $2 \% \mathrm{CaCl}_{2}$ solution for $6 \mathrm{~h}(\mathrm{P})$, the other part of a nonprimed (NP) seeds was soaked in $\mathrm{H}_{2} \mathrm{O}$. Sterilized seeds of both parts ( $P$ and NP) were germinated in $15 \mathrm{~cm}$ in diameter plastic pots filled with acid-washed and sterilized sand used as a growth support and supplied with half strength Hoagland solution (Hoagland and Arnon 1938). After $7 \mathrm{~d}$ from sowing, the medium was changed to fullstrength Hoagland solution (containing 0 or $50 \mu \mathrm{M} \mathrm{Cd}$ ). Pots were saturated daily with $300 \mathrm{~mL}$ of solution. The seedlings were grown for 3 weeks $(21 \mathrm{~d})$ in a greenhouse at a day/night cycle of $12 / 12 \mathrm{~h}$, at $23 / 18^{\circ} \mathrm{C}$, respectively; relative humidity was approximately $70 \%$.

Gas exchange and $\mathrm{Chl}$ fluorescence: After three weeks of $\mathrm{Cd}$ treatment $(0$ or $50 \mu \mathrm{M} \mathrm{Cd})$, gas-exchange attributes, such as net $\mathrm{CO}_{2}$ assimilation rate $\left(P_{\mathrm{N}}\right)$, stomatal conductance $\left(g_{\mathrm{s}}\right)$, intracellular $\mathrm{CO}_{2}$ concentration $\left(C_{\mathrm{i}}\right)$, transpiration rate $(E)$, and water-use efficiency [WUE, the ratio between carbon gain in photosynthesis $\left(P_{\mathrm{N}}\right)$ and water loss in transpiration $(E)$ ] were determined on the youngest and fully expanded top leaves by using an open type and portable photosynthesis system (LCA-4, Bio-Scientific, Great Amwell, Herts, UK) under the following conditions: saturating light intensity of about $1,350 \mu \mathrm{mol}$ (photon) $\mathrm{m}^{-2} \mathrm{~s}^{-1}, \mathrm{CO}_{2}$ concentration of $380 \mu \mathrm{mol} \mathrm{mol} \mathrm{mo}^{-1}$, leaf temperature of $27 \pm 2{ }^{\circ} \mathrm{C}$, and relative humidity was $65 \pm 5 \%$.

$\mathrm{Chl}$ fluorescence was monitored using a modulated Chl fluorimeter (OS1-FL, Opti-Sciences, Tyngsboro, MA, USA). Leaves previously selected for the measurement of photosynthetic gas exchange were used for Chl fluorescence measurements following the procedure described by Genty et al. (1989). After a dark-adaptation period of $30 \mathrm{~min}$, the minimal $\mathrm{Chl}$ fluorescence $\left(\mathrm{F}_{0}\right)$ was determined by a weak red light pulse (6 s). Maximum fluorescence of dark-adapted state $\left(\mathrm{F}_{\mathrm{m}}\right)$ was measured during a subsequent saturating pulse of white light $\left[8,000 \mu \mathrm{mol}\left(\right.\right.$ photon) $\mathrm{m}^{-2} \mathrm{~s}^{-1}$ for $0.8 \mathrm{~s}]$.

The maximal photochemical efficiency of PSII $\left(\mathrm{F}_{\mathrm{v}} / \mathrm{F}_{\mathrm{m}}\right)$ was expressed as: $F_{\mathrm{v}} / \mathrm{F}_{\mathrm{m}}=\left(\mathrm{F}_{\mathrm{m}}-\mathrm{F}_{0}\right) / \mathrm{F}_{\mathrm{m}}$. The relative quantum yield of PSII at steady state was calculated as $\Phi_{\text {PSII }}=\left(F_{\mathrm{m}}{ }^{\prime}-\mathrm{F}_{\mathrm{s}}\right) / \mathrm{F}_{\mathrm{m}}{ }^{\prime}$, where $\mathrm{F}_{\mathrm{s}}$ and $\mathrm{F}_{\mathrm{m}}{ }^{\prime}$ are fluorescence at steady state and maximum fluorescence in the light, respectively. The nonphotochemical quenching coefficient (NPQ), describing regulated dissipation of excess energy, was estimated as $\left(\mathrm{F}_{\mathrm{m}}-\mathrm{F}_{\mathrm{m}}{ }^{\prime}\right) / \mathrm{F}_{\mathrm{m}}{ }^{\prime}$ (Bilger et al. 2001). The linear electron transport rate (ETR) was calculated using the equation: $\mathrm{ETR}=\mathrm{PAR} \times 0.5 \times \Phi_{\mathrm{PSII}} \times 0.84$, where PAR is the photosynthetic active radiation, 0.5 is distribution of energy between the two photosystems, and 0.84 is a fraction of light energy absorbed by a leaf (Genty et al. 1989). All Chl fluorescence measurements were taken from 11:00 to 13:00 h. The mean of the six measurements was calculated and used for each treatment.

Chl determination: Leaf $\mathrm{Chl} a, b$, and carotenoid (Car) concentrations of the NP or P faba bean plants were determined three weeks after cadmium application by the method of Lichtenthaler and Wellburn (1983). Fresh leaf tissues $(0.3 \mathrm{~g})$ from fully expanded healthy leaves were ground and extracted with $10 \mathrm{~mL}$ of $80 \%(\mathrm{v} / \mathrm{v})$ acetone. The suspension was centrifuged at $4^{\circ} \mathrm{C}$ for $5 \mathrm{~min}$ at $5,000 \times g$ and absorbance was measured at 470,646, and $663 \mathrm{~nm}$, using a UV-visible spectrophotometer (Jenway 6850 UV-Vis, Cole-Parmer Ltd., UK). The pigment content [expressed as $\mathrm{mg} \mathrm{g}^{-1}(\mathrm{FM})$ ] was calculated by using the following equations:

Chl $a=13.95 \times \mathrm{A}_{665}-6.88 \times \mathrm{A}_{649}$

Chl $b=24.96 \times \mathrm{A}_{649}-7.32 \times \mathrm{A}_{665}$

$\mathrm{Car}=\left(1,000 \times \mathrm{A}_{470}-2.05 \times \mathrm{Chl} a-114.8 \times \mathrm{Chl} b\right) / 245$

Electrolyte leakage (EL) determination: The total inorganic ions leaked out in the leaves were estimated by the method of Dionisio-Sese and Tobita (1998). Twenty leaf discs were taken in a boiling tube containing $10 \mathrm{~mL}$ of deionized water and electrical conductivity $\left(\mathrm{EC}_{\mathrm{a}}\right)$ was measured (Conductivity Model Consort K912, CONSORTPARKLAAN, Belgium). The contents were heated at $45^{\circ} \mathrm{C}$ and $55^{\circ} \mathrm{C}$ for $30 \mathrm{~min}$ in a water bath and electrical conductivity $\left(\mathrm{EC}_{\mathrm{b}}\right)$ was measured. Later, the content was again boiled at $100^{\circ} \mathrm{C}$ for $10 \mathrm{~min}$ and electrical conductivity $\left(\mathrm{EC}_{\mathrm{c}}\right)$ was again recorded. The EL was calculated by using the formula: $\mathrm{EL}[\%]=\left(\mathrm{EC}_{\mathrm{b}}-\mathrm{EC}_{\mathrm{a}}\right) /\left(\mathrm{EC}_{\mathrm{c}}-\mathrm{EC}_{\mathrm{a}}\right) \times 100$.

Histochemical detection of $\mathrm{H}_{2} \mathrm{O}_{2}$ and $\mathrm{O}_{2}{ }^{--}$: In situ accumulations of superoxide radical and hydrogen peroxide were examined with histochemical staining protocols. Location of $\mathrm{O}_{2}^{-}$in faba bean leaf discs was determined using the nitroblue tetrazolium (NBT) reduction test described by Dutilleul et al. (2003). Leaf discs were sampled and immediately vacuum-infiltrated in $0.5 \mathrm{mg}(\mathrm{NBT}) \mathrm{mL}^{-1}$ and $10 \mathrm{mM}$ potassium phosphate buffer at $\mathrm{pH}$ 7.8. After being incubated in dark at room temperature for $1 \mathrm{~h}$, samples were cleared in $90 \%$ ethanol at $70^{\circ} \mathrm{C}$ to remove $\mathrm{Chl} . \mathrm{O}_{2}{ }^{--}$was visualized as a blue color at the site of NBT precipitation. The stained discs were transferred into Petri dishes, analysed, and photographed under a binocular microscope (Leica 56E, Leica Microsystems, Wetzlar, Germany) coupled with 
a digital camera. Histochemical changes in $\mathrm{H}_{2} \mathrm{O}_{2}$ were studied by using starch-potassium iodide (KI) method (Olson and Varner 1993). Leaf discs were incubated on a solid medium (4\% starch, $0.1 \mathrm{M} \mathrm{KI}, 1.0 \mathrm{M}$ glucose, and $0.8 \%$ agarose) for $4 \mathrm{~h}$ at room temperature for color development. To quantify the stained areas, digital images of leaf discs were converted into grayscale images and the percentage of stained spot areas to the total leaf disc areas were determined with Image $J$ software (Image $J$, ver. $1.51 p$, Wayne Rasband, National Institutes of Health, USA).

Statistical analysis: All data are presented as means \pm $\mathrm{SD}$ of at least five replicate seedlings. One-way analysis of variance (ANOVA) was performed in SPSS program version 20.0 (SPSS, Chicago, USA). Comparisons between the mean values were accomplished by the least significant difference $(L S D)$ test at the level of $p \leq 0.05$. All graphs were made using SigmaPlot version 11.0 (Systat).

\section{Results}

Chlorophylls and gas-exchange attributes: In NP plants, results showed that the $P_{\mathrm{N}}, E, g_{\mathrm{s}}, C_{\mathrm{i}}$, and WUE values significantly decreased under $50 \mu \mathrm{M} \mathrm{Cd}$ treatment by
$64,42,69,55$, and $37 \%$, respectively, as compared with controls (Fig. 1). In contrast, $\mathrm{CaCl}_{2}$ seed priming improved the photosynthetic parameters under $\mathrm{Cd}$ stress conditions and increased $P_{\mathrm{N}}, E, g_{\mathrm{s}}, C_{\mathrm{i}}$, and WUE by $88,48,95,68$, and $27 \%$, respectively, compared to Cd-stressed plants alone (Fig. 1). Thus, these results revealed that $\mathrm{CaCl}_{2}$ seed priming could improve photosynthetic activity and alleviate $\mathrm{Cd}$-induced photosynthetic changes in faba bean plants.

The growth retardation of faba bean plants (Fig. 2) by the $\mathrm{Cd}$ application $(50 \mu \mathrm{M})$, was found to be associated with a significant decrease in Chl $a$ and $\mathrm{Chl} b$ contents (by 53 and 59\%, respectively, as compared with the Cd-free control plants) (Fig. 3). However, $\mathrm{CaCl}_{2}$ pretreatment (P) significantly alleviated this Cd-induced inhibition; Chl $a$, Chl $b$, and Car increased by 30,67, and 73\%, respectively, compared with a Cd-stressed plants (NP with $50 \mu \mathrm{M} \mathrm{Cd}$ ). Moreover, results indicated that $\mathrm{CaCl}_{2}$-pretreated plants (P) exhibited significant increases in $\mathrm{Chl} a, \mathrm{Chl} b$, and Car values (by 17, 4, and 54\%, respectively) compared with the Cd-free control (NP at $0 \mu \mathrm{M} \mathrm{Cd}$ ) (Fig. 3).

Chl fluorescence: Under Cd treatment $(50 \mu \mathrm{M})$, Chl fluorescence parameters $\left(\mathrm{F}_{\mathrm{v}} / \mathrm{F}_{\mathrm{m}}, \Phi_{\mathrm{PSII}}\right.$, and ETR $)$ declined by 14,7 , and $23 \%$, respectively, as compared with control

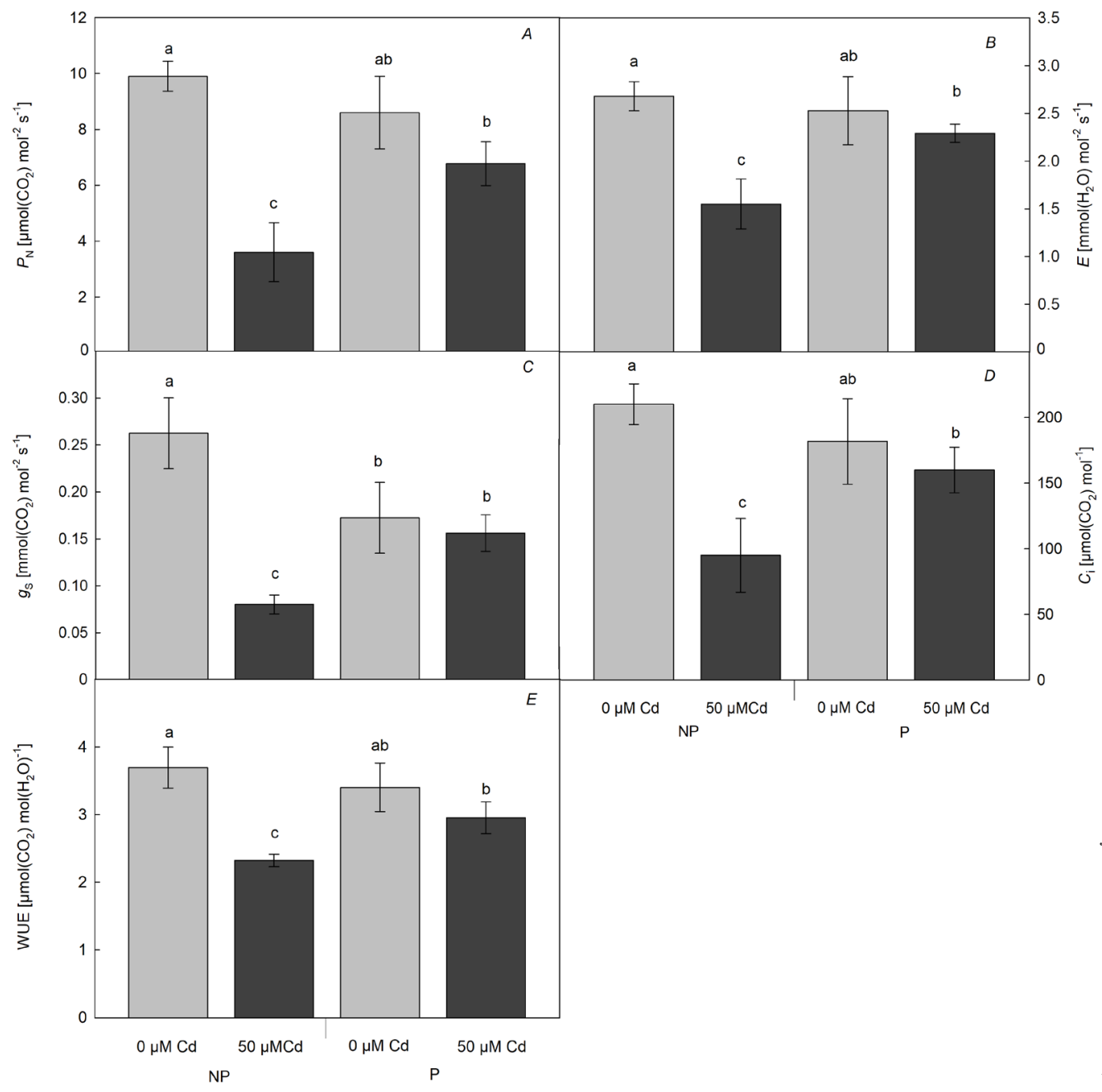

Fig. 1. Cadmium effect on net photosynthetic rate, $P_{\mathrm{N}}(A)$, transpiration rate, $E(B)$, stomatal conductance, $g_{\mathrm{s}}(C)$, intracellular $\mathrm{CO}_{2}$ content, $C_{\mathrm{i}}(D)$, and water-use efficiency, WUE $(E)$ in Vicia faba plants pretreated with $2 \% \mathrm{CaCl}_{2}(\mathrm{P})$ or $\mathrm{H}_{2} \mathrm{O}(\mathrm{NP})$ for $6 \mathrm{~h}$ and growing for 21 days under 0 or $50 \mu \mathrm{M} \mathrm{Cd}$. Values are the means of five replications $\pm \mathrm{SD}$. The data followed by different letters are significantly different at $p \leq 0.05$. 


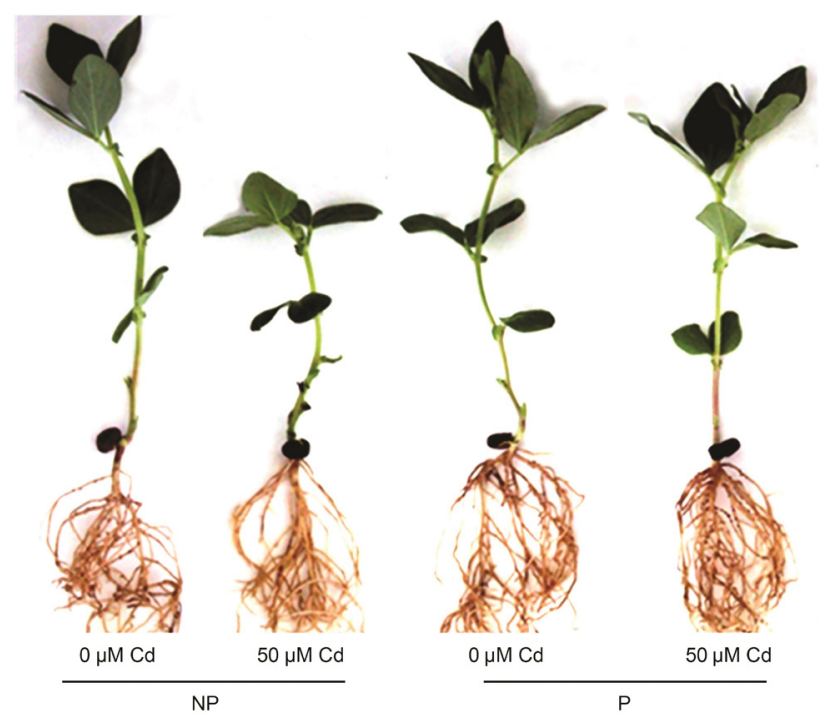

Fig. 2. Vicia faba L. plants pretreated with $2 \% \mathrm{CaCl}_{2}(\mathrm{P})$ or with $\mathrm{H}_{2} \mathrm{O}(\mathrm{NP})$ for $6 \mathrm{~h}$, and growing for 21 days under 0 or $50 \mu \mathrm{M} \mathrm{Cd}$.

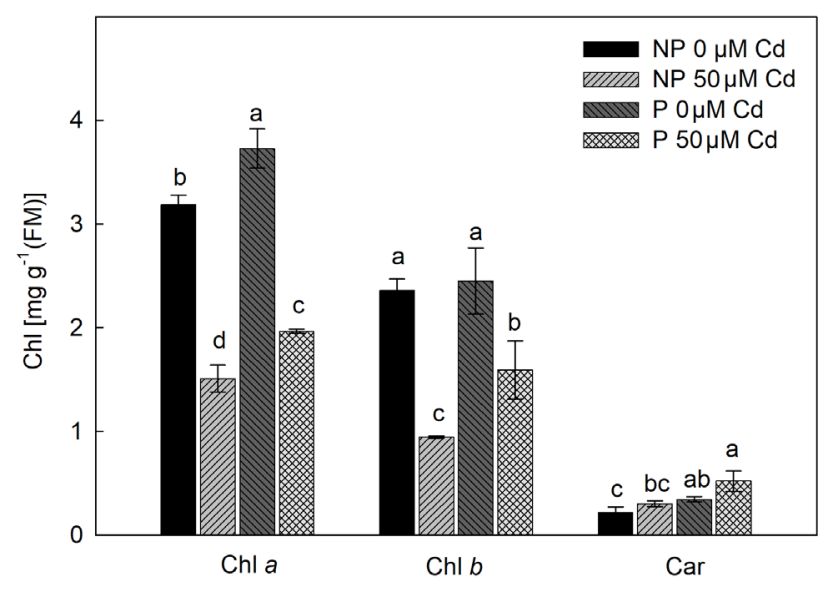

Fig. 3. Chlorophyll (Chl) $a, \mathrm{Chl} b$, and carotenoids (Car) in leaves of Vicia faba plants pretreated with $2 \% \mathrm{CaCl}_{2}(\mathrm{P})$ or $\mathrm{H}_{2} \mathrm{O}(\mathrm{NP})$ for $6 \mathrm{~h}$ and growing for 21 days under 0 or $50 \mu \mathrm{M} \mathrm{Cd}$. Values are the means of 12 replications \pm SD. The data followed by different letters are significantly different at $p \leq 0.05$.

(Fig. 4A,B,D). The value of NPQ under $\mathrm{Cd}$ treatment exhibited an increase of $20 \%$ in comparison with control (Fig. 4C). Furthermore, in Cd-treated faba bean plants, $\mathrm{CaCl}_{2}$ pretreatment showed significant improvement in the values of $\mathrm{F}_{\mathrm{v}} / \mathrm{F}_{\mathrm{m}}, \Phi_{\text {PSII }}$, and ETR compared to Cd-stressed plants alone. In contrast to this finding, the value of NPQ declined significantly in $\mathrm{CaCl}_{2}$-pretreated plants subjected to $\mathrm{Cd}$ stress compared to $\mathrm{Cd}$-stressed plants alone (Fig. 4C).

$\mathrm{H}_{2} \mathrm{O}_{2}$ and $\mathrm{O}_{2}{ }^{-}$production: Endogenous $\mathrm{O}_{2}{ }^{-}$in leaf tissues was stained with NBT to form a dark blue insoluble formazan compound. As expected, the generation of $\mathrm{O}_{2}^{-{ }^{-}}$ increased in leaves considerably in response to the $\mathrm{Cd}$ treatment. However, $\mathrm{CaCl}_{2}$ seed pretreatment reduced $\mathrm{O}_{2}{ }^{-}$generation in leaves of Cd-treated plants (Fig. 5A). To verify in situ the accumulation of $\mathrm{H}_{2} \mathrm{O}_{2}$ in faba bean leaves, a histochemical method with starch-KI, based on the formation of local brown spots by $\mathrm{H}_{2} \mathrm{O}_{2}$ in leaves, was used (Fig. $5 B$ ). Under $50 \mu \mathrm{M} \mathrm{CdCl}_{2}$ treatment, $\mathrm{H}_{2} \mathrm{O}_{2}$ accumulation was high in leaves of faba bean seedlings. However, $\mathrm{CaCl}_{2}$ seed pretreatment decreased intensity of brown deposit in leaves of Cd-treated seedlings indicating lower concentration of $\mathrm{H}_{2} \mathrm{O}_{2}$ (Fig. $5 B$ ).

EL: Membrane stability decreased significantly with $\mathrm{Cd}$ stress $(50 \mu \mathrm{M})$ in control plants (NP). An increase (by $61 \%$ ) in the EL under $50 \mu \mathrm{M} \mathrm{Cd}$ treatment was observed (Fig. 6). However, in Cd-treated faba bean plants, $\mathrm{CaCl}_{2}$ pretreatment showed significant improvement of the values of EL compared with a Cd-stressed plants.

\section{Discussion}

The reported research was undertaken to improve our understanding of physiological processes determining heavy metal tolerance and the induction of such processes by $\mathrm{CaCl}_{2}$ seed priming for the alleviation of $\mathrm{Cd}$-induced decreases in photosynthesis. In the present study, plant growth and photosynthetic parameters decreased under Cd stress (Figs. 1,2). Cadmium-induced inhibition in plant growth has already been reported in many plant species, such as wheat (Rizwan et al. 2012), rice (Cao et al. 2013), maize (Vaculík et al. 2015), Brassica napus (Nouairi et al. 2006), tomato (Ammar et al. 2015), and bean plants (Saidi et al. 2013). It has been shown that photosynthesis was closely related to plant growth and biomass production. Therefore, the decrease in plant growth might be due to Cd-induced toxicity on photosynthetic apparatus (Bashir et al. 2015, Moradi and Ehsanzadeh 2015) and/or structural alterations in plants (Nouairi et al. 2006, Belkhadi et al. 2010). Decrease in plant growth and biomass might also be due to oxidative damage and reduction in antioxidant enzymes activities (Ahmad et al. 2009) and/or reduction in mineral nutrients uptake by plants (Ben Ghnaya et al. 2009). It might be assumed that this decrease in plant growth could be due to the reduced cell expansion (Daud et al. 2013), decrease of Calvin-cycle enzymes, inhibition of the photosynthetic electron transport chain, and might also be due to $\mathrm{Cd}$-induced inhibition in gas-exchange characteristics and Chl contents (Ali et al. 2014, Per et al. 2016).

In the present investigation, it was found that $\mathrm{CaCl}_{2}$ seed priming markedly alleviated $\mathrm{Cd}$-induced reduction in growth and photosynthetic parameters in faba bean plants (Figs. 1,2). Indeed, under Cd stress, results indicated that $\mathrm{CaCl}_{2}$ pretreatment caused significant increases in $g_{\mathrm{s}}, C_{\mathrm{i}}$, and $E$ values. Thus, these results suggested that $\mathrm{CaCl}_{2}$ could alleviate the stomata closure caused by $\mathrm{Cd}$ and promote the photosynthesis by ensuring the transport of abundant $\mathrm{CO}_{2}$ to the chloroplast. Moreover, the $\mathrm{Cd}$-induced $\mathrm{Chl}$ content reduction was significantly reversed when faba bean seeds were treated with $2 \% \mathrm{CaCl}_{2}$ (Fig. 3). This indicated that $\mathrm{Ca}^{2+}$ pretreatment mediated improvement 


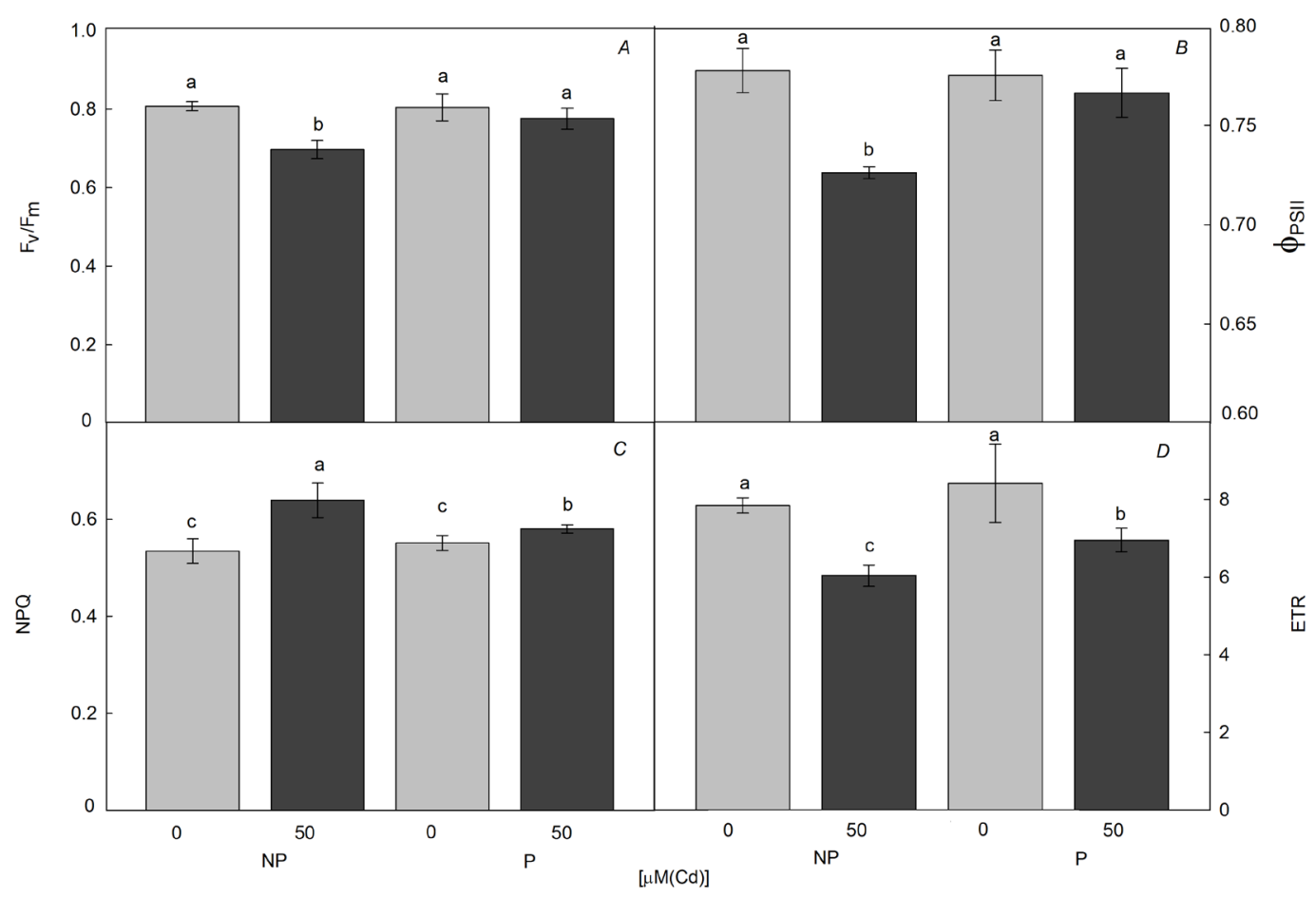

Fig. 4. Cadmium effect on the maximum quantum yield of PSII photochemistry, $\mathrm{F}_{\mathrm{v}} / \mathrm{F}_{\mathrm{m}}(A)$, quantum efficiency of PSII photochemistry, $\Phi_{\text {PSII }}(B)$, nonphotochemical quenching, NPQ $(C)$, and the relative PSII electron transport rate, ETR $(D)$ in Vicia faba plants pretreated with $2 \% \mathrm{CaCl}_{2}(\mathrm{P})$ or $\mathrm{H}_{2} \mathrm{O}(\mathrm{NP})$ for $6 \mathrm{~h}$ and growing for 21 days under 0 or $50 \mu \mathrm{M} \mathrm{Cd}$. Values are the means of 6 replications $\pm \mathrm{SD}$. The data followed by different letters are significantly different at $p \leq 0.05$.

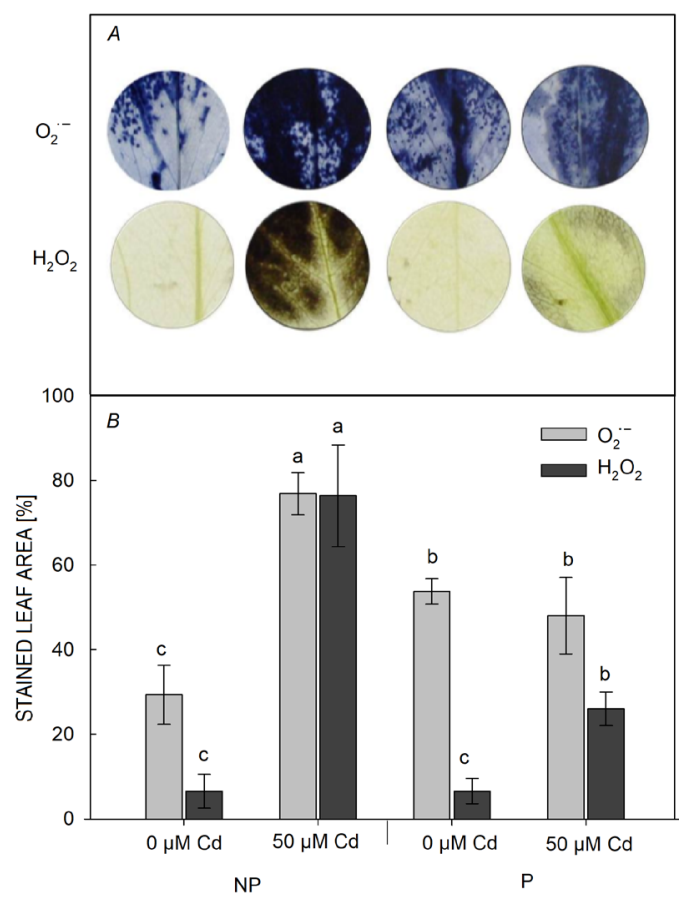

Fig. 5. Histochemical detection of $\mathrm{O}_{2}^{-}$and $\mathrm{H}_{2} \mathrm{O}_{2}(A)$ and the percentage of the stained leaf area $(B)$ in leaves of Vicia faba plants pretreated with $2 \% \mathrm{CaCl}_{2}(\mathrm{P})$ or with $\mathrm{H}_{2} \mathrm{O}(\mathrm{NP})$ for $6 \mathrm{~h}$ and growing for 21 days under 0 or $50 \mu \mathrm{M} \mathrm{Cd}$. Values are the means of 6 replications $\pm \mathrm{SD}$. The data followed by different letters are significantly different at $p \leq 0.05$.

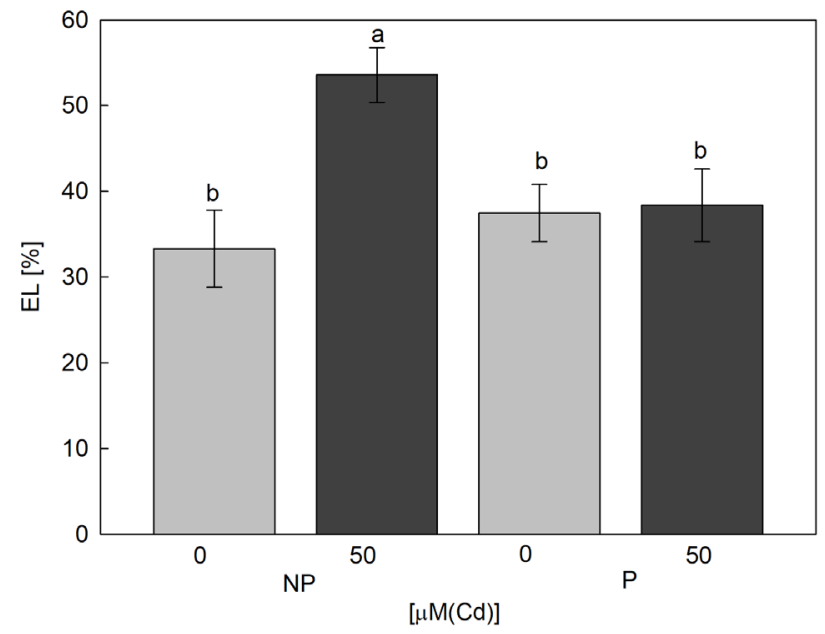

Fig. 6. Electrolyte leakage (EL) in leaves of Vicia faba plants pretreated with $2 \% \mathrm{CaCl}_{2}(\mathrm{P})$ or with $\mathrm{H}_{2} \mathrm{O}(\mathrm{NP})$ for $6 \mathrm{~h}$ and growing for 21 days under 0 or $50 \mu \mathrm{M} \mathrm{Cd}$. Values are the means of 10 replications $\pm \mathrm{SD}$. The data followed by different letters are significantly different at $p \leq 0.05$.

in photosynthesis, partly due to increasing Chl synthesis. Moreover, it has been shown that $\mathrm{Ca}^{2+}$ served as secondary messenger for cytokinin action in improving synthesis of Chl (Lechowski and Bialczyk 1993).

Indeed, it has been reported by many researchers that exogenous application of $\mathrm{Ca}^{2+}$ enhanced the plant 
tolerance to heavy metals (Farzadfar et al. 2013, Lwalaba et al. 2017) and other stresses (Jiang et al. 2001, Xu et al. 2013, Methenni et al. 2018). $\mathrm{Ca}^{2+}$-mediated biomass enhancement might occur due to an increase in the uptake of nutrients by plants under stressful conditions (Khan et al. 2012, Siddiqui et al. 2012). Calcium may maintain the photosynthetic capacity of plants by increasing stomatal conductance and maintaining Rubisco activity and chloroplast ultrastructure under abiotic stress (Liang et al. 2009, Tan et al. 2011, Xu et al. 2017). The Chl fluorescence technique has been proven to be a sensitive method for the detection and quantification of changes induced in the photosynthetic apparatus. This analysis permits detection, monitoring, and evaluation of abiotic stresses upon healthy plants (da Silva et al. 2012). The $\mathrm{F}_{\mathrm{v}} / \mathrm{F}_{\mathrm{m}}$ and photochemical quenching coefficient $\left(\mathrm{q}_{\mathrm{P}}\right)$ are frequently used to measure the maximum photochemical efficiency of PSII and proportion of oxidized (open) reaction centres PSII, respectively, while $\mathrm{F}_{\mathrm{v}} / \mathrm{F}_{0}$ (activity of PSII) and $\mathrm{F}_{\mathrm{m}} / \mathrm{F}_{0}$ (electron transport through PSII) are also used to explore the photosynthetic efficiency of plants in changing environmental conditions (Xing et al. 2010). Studies demonstrate that stress factors generally affect functional activity of PSII and thus decrease these ratios (Xing et al. 2010). Under Cd stress, the decline in $\mathrm{F}_{\mathrm{v}} / \mathrm{F}_{\mathrm{m}}, \Phi_{\mathrm{PSII}}$, and ETR (Fig. 4) indicated structural and functional alterations in photosynthetic process as evidenced by decreased growth of faba bean plants (Fig. 2). In addition, the NPQ value significantly increased under Cd stress $(50 \mu \mathrm{M})$, indicating that an antenna pigment could not effectively transform light energy into chemical energy and it was, therefore, released as heat (Zou et al. 2015).

On the other hand, $\mathrm{CaCl}_{2}$ seed priming significantly alleviated $\mathrm{Cd}$-induced damaging effects on photosynthesis (Fig. 4), which could be correlated with improved photosynthetic efficiency of faba bean plants. Moreover, under $\mathrm{Cd}$ stress, in $\mathrm{CaCl}_{2}$-pretreated plants, the NPQ value remarkably decreased, suggesting that $\mathrm{CaCl}_{2}$ improved the light-utilisation efficiency.

Another protective mechanism of $\mathrm{CaCl}_{2}$ seed pretreatment in alleviating $\mathrm{Cd}$ toxicity was via eliminating free radical-induced damage caused by $\mathrm{Cd}$. Previous studies have shown that $\mathrm{Cd}$ toxicity resulted in the accumulation of ROS and oxidation of lipid membranes (Chaoui et al. 1997, Nouairi et al. 2006). In the current study, Cdstressed faba bean plants had the increased $\mathrm{O}_{2}{ }^{-}$and $\mathrm{H}_{2} \mathrm{O}_{2}$ accumulation and EL (Figs. 5,6). However, $\mathrm{CaCl}_{2}$ seed pretreatment significantly lowered the ROS overproduction and decreased EL in leaves of Cd-stressed plants. The Ca-induced inhibition of EL and ROS contents indicates that $\mathrm{CaCl}_{2}$ seed priming could significantly alleviate the harmful effects of Cd stress in faba bean plants. Moreover, our results suggest that calcium alleviated the adverse effect of the oxidative stress by reducing the content of $\mathrm{O}_{2}{ }^{-}$ and $\mathrm{H}_{2} \mathrm{O}_{2}$ possibly through stimulation of ROS-scavenging enzymes, such as superoxide dismutase (SOD), catalase (CAT), guaiacol peroxidase (GPX), and enhancement of nonprotein thiol $(-\mathrm{SH})$ contents in leaves of faba bean Cd-stressed plants (Nouairi et al. 2012). In addition, $\mathrm{Ca}^{2+}$ is one of many cellular network parameters orchestrating complex cellular signalling coordinating responses to numerous developmental cues and environmental challenges. It has been shown that $\mathrm{Ca}^{2+}$ had the function of preventing cell membrane injury and leakage as well as stabilizing cell membranes under adverse environmental conditions (Guimarães et al. 2011, Nouairi et al. 2012). Indeed, it has been demonstrated that a high concentration of $\mathrm{Ca}^{2+}$ around plasma membrane reduces cell-surface negativity and harmfulness of cationic toxicants (Kinraide 1998) or the uptake of Cd via calcium channels to mimic $\mathrm{Ca}$ (Suzuki 2005). Thus, seed priming with $\mathrm{CaCl}_{2}$ seems to play a fundamental role in the establishment of a basal resistance to environmental stresses.

Conclusion: Taken together, the overall results from this research suggest that Cd significantly inhibited the growth traits as well as the photosynthetic parameters in faba bean seedlings. It is suggested that Cd acts as the main limiting factors for photosynthesis via Chl loss, changes in the photosynthetic apparatus, and damage of PSII reaction centre. However, seed priming with $\mathrm{CaCl}_{2}$ significantly alleviated $\mathrm{Cd}$-induced inhibition of faba bean growth, chlorophyll contents, gas-exchange attributes, and photosynthetic efficiency. $\mathrm{CaCl}_{2}$ pretreatment markedly reduced $\mathrm{Cd}$-induced ROS accumulation and EL, and might be an important technique that enables the plants to tolerate abiotic stress.

\section{References}

Agami R.A., Mohamed G.F.: Exogenous treatment with indole3 -acetic acid and salicylic acid alleviates cadmium toxicity in wheat seedlings. - Ecotox. Environ. Safe. 94: 164-171, 2013.

Ahmad I., Naeem M., Khan N.A., Samiullah: Effects of cadmium stress upon activities of antioxidative enzymes, photosynthetic rate, and production of phytochelatins in leaves and chloroplasts of wheat cultivars differing in yield potential. - Photosynthetica 47: 146-151, 2009.

Ali B., Qian P., Jin R. et al:: Physiological and ultra-structural changes in Brassica napus seedlings induced by cadmium stress. - Biol. Plantarum 58: 131-138, 2014.

Ammar W.B., Zarrouk M., Nouairi I.: Zinc alleviates cadmium effects on growth, membrane lipid biosynthesis and peroxidation in Solanum lycopersicum leaves. - Biologia 70: 198-207, 2015.

Antosiewicz D.M., Hennig J.: Overexpression of LCT1 in tobacco enhances the protective action of calcium against cadmium toxicity. - Environ. Pollut. 129: 237-245, 2004.

Bashir H., Qureshi M.I., Ibrahim M.M., Iqbal M.: Chloroplast and photosystems: Impact of cadmium and iron deficiency. Photosynthetica 53: 321-335, 2015.

Belkhadi A., Hediji H., Abbes Z. et al.: Effects of exogenous salicylic acid pretreatment on cadmium toxicity and leaf lipid content in Linum usitatissimum L. - Ecotox. Environ. Safe. 73: 1004-1011, 2010.

Ben Ghnaya A., Charles G., Hourmant A. et al.: Physiological behaviour of four rapeseed cultivar (Brassica napus L.) submitted to metal stress. - C. R. Biol. 332: 363-370, 2009.

Bilger W., Johnsen T., Schreiber U.: UV-excited chlorophyll fluorescence as a tool for the assessment of UV-protection by the epidermis of plants. - J. Exp. Bot. 52: 2007-2014, 2001.

Cao F., Liu L., Ibrahim W. et al:: Alleviating effects of exogenous glutathione, glycinebetaine, brassinosteroids and salicylic 
acid on cadmium toxicity in rice seedlings (Oryza sativa).Agrotechnology 2: doi: 10.4172/2168-9881.1000107, 2013.

Chaoui A., Mazhoudi S., Habib Ghorbal M., El Ferjani E.: Cadmium and zinc induction of lipid peroxidation and effects on antioxidant enzyme activities in bean (Phaseolus vulgaris L.). - Plant Sci. 127: 139-147, 1997.

Chen X.T., Wang G., Liang Z.C.: Effect of amendments on growth and element uptake of pakchoi in a cadmium, zinc and lead contaminated soil. - Pedosphere 12: 243-250, 2002.

da Silva A.J., do Nascimento C.V.A., da Silva Gouveia-Neto A., da Silva, E.A.: LED-induced chlorophyll fluorescence spectral analysis for the early detection and monitoring of cadmium toxicity in maize plants. - Water Air Soil Poll. 223: 3527-3533, 2012.

Daud M.K., Ali S., Variath M.T., Zhu S.J.: Differential physiological, ultramorphological and metabolic responses of cotton cultivars under cadmium stress. - Chemosphere 93: 25932602, 2013.

Daud M.K., Variath M.T., Shafaqat A. et al.: Cadmium-induced ultramorphological and physiological changes in leaves of two transgenic cotton cultivars and their wild relative. - J. Hazard. Mater. 168: 614-625, 2009.

Delian E., Chira A., Badulescu L., Chira L.: Calcium alleviates stress in plants: Insight into regulatory mechanisms. AgroLife Sci. J. 3: 19-28, 2014.

Dionisio-Sese M.L., Tobita S.: Antioxidant responses of rice seedlings to salinity stress. - Plant Sci. 135: 1-9, 1998.

Dixit V., Pandey V., Shymar R.: Differential antioxidative responses to cadmium in roots and leaves of pea (Pisum sativum L. cv. Azard). - J. Exp. Bot. 52: 1101-1109, 2001.

Dutilleul C., Garmier M., Noctor G. et al.: Leaf mitochondria modulate whole cell redox homeostasis, set antioxidant capacity, and determine stress resistance through altered signaling and diurnal regulation. - Plant Cell 15: 1212-1226, 2003.

Ekmekçi Y., Tanyolaç D., Ayhan B.: Effects of cadmium on antioxidant enzyme and photosynthetic activities in leaves of two maize cultivars. - J. Plant Physiol. 165: 600-611, 2008.

Farzadfar S., Zarinkamar F., Modarres-Sanavy S.A., Hojati M.: Exogenously applied calcium alleviates cadmium toxicity in Matricaria chamomilla L. plants. - Environ. Sci. Pollut. R. 20: 1413-1422, 2013.

Genty B., Briantais J.M., Baker N.R.: The relationship between the quantum yield of photosynthetic electron transport and quenching of chlorophyll fluorescence. - Biochim. Biophys. Acta 990: 87-92, 1989.

Guimarães F.V.A., de Lacerda C.F., Marques E.C. et al.: Calcium can moderate changes on membrane structure and lipid composition in cowpea plants under salt stress. - Plant Growth Regul. 65: 55-63, 2011.

Hironari N., Takashi S.: Calcium signaling in plant endosymbiotic organelles: Mechanism and role in physiology. - Mol. Plant 7: 1094-1104, 2014.

Hoagland D.R., Arnon D.I.: The water culture method for growing plants without soil. - In: California Agricultural Experiment Station Circular No. 347. Pp. 39. University of California, Berkeley 1938.

Ismail M.A.: Involvement of $\mathrm{Ca}^{2+}$ in alleviation of $\mathrm{Cd}^{2+}$ toxicity in common bean (Phaseolus vulgaris L.) plants. - Asian J. Bio. Sci. 1: 26-32, 2008.

Jiang T. Zhan X., Xu Y. et al.: Roles of calcium in stress-tolerance of plants and its ecological significance. - Chin. J. Appl. Ecol. 16: 971-976, 2005

Jiang Y., Huang B.: Effects of calcium on antioxidant activities and water relations associated with heat tolerance in two coolseason grasses. - J. Exp. Bot. 52: 341-349, 2001.
Karadaş C., Kara D.: In vitro gastro-intestinal method for the assessment of heavy metal bioavailability in contaminated soils. - Environ. Sci. Pollut. R. 18: 620-628, 2011.

Khan M.N., Siddiqui M.H., Mohammad F., Naeem M.: Interactive role of nitric oxide and calcium chloride in enhancing tolerance to salt stress. - Nitric Oxide 27: 210-218, 2012.

Kinraide T.B.: Three mechanisms for the calcium alleviation of mineral toxicities. - Plant Physiol. 118: 513-520, 1998.

Lechowski Z., Bialczyk J.: Calcium mediated cytokinin action on chlorophyll synthesis in isolated embryo of Scots pine. Biol. Plantarum 35: 53-62, 1993.

Liang W., Wang M., Ai X.: The role of calcium in regulating photosynthesis and related physiological indexes of cucumber under low light intensity and suboptimal temperature stress. Sci. Hortic.-Amsterdam 123: 34-38, 2009.

Lichtenthaler K., Welburn A.R.: Determination of total carotenoids and chlorophylls $a$ and $b$ of leaf extracts in different solvents. - Biochem. Soc. T. 11: 591-592, 1983.

Lwalaba J.L., Zvobgo G., Fu L. et al.: Alleviating effects of calcium on cobalt toxicity in two barley genotypes differing in cobalt tolerance. - Ecotox. Environ. Safe. 139: 488-495, 2017.

Methenni K., Ben Abdallah M., Nouairi I. et al.: Salicylic acid and calcium pretreatments alleviate the toxic effect of salinity in the Oueslati olive variety. - Sci. Hortic.-Amsterdam 233: 349-358, 2018.

Miller G., Shulaev V., Mittler R.: Reactive oxygen signaling and abiotic stress. - Physiol. Plantarum 133: 481-489, 2008.

Moradi L., Ehsanzadeh P.: Effects of Cd on photosynthesis and growth of safflower (Carthamus tinctorius L.) genotypes. Photosynthetica 53: 506-518, 2015.

Najeeb U., Jilani G., Ali S. et al.: Insight into cadmium induced physiological and ultra-structural disorders in Juncus effusus L. and its remediation through exogenous citric acid. - J. Hazard. Mater. 186: 565-574, 2011.

Nouairi I., Ben Ammar W., Ben Youssef N. et al.: Comparative study of cadmium effects on membrane lipid composition of Brassica juncea and Brassica napus leaves. - Plant Sci. 170: 511-519, 2006.

Nouairi I., Methanni K., Mhadhbi H., Jebara M.: Effects of $\mathrm{CaCl}_{2}$ pretreatment on antioxidant enzyme and leaf lipid content of faba bean (Vicia faba L.) seedlings under cadmium stress. Plant Growth Regul. 68: 37-47, 2012.

Olson P.D., Varner J.E.: Hydrogen peroxide and lignification. Plant J. 4: 887-892, 1993.

Paparella S., Araújo S.S., Rossi G. et al.: Seed priming: state of the art and new perspectives. - Plant Cell Rep. 34: 1281-1293, 2015.

Per T.S., Khan S., Asgher M. et al.: Photosynthetic and growth responses of two mustard cultivars differing in phytocystatin activity under cadmium stress. - Photosynthetica 54: 491501, 2016.

Prasad M.N.V.: Cadmium toxicity and tolerance in vascular plants. - Environ. Exp. Bot. 35: 525-545, 1995.

Qadir M., Ghafoor A., Murtaza G.: Cadmium concentration in vegetables grown on urban soils irrigated with untreated municipal sewage. - Environ. Dev. Sustain. 2: 13-21, 2000.

Rizwan M., Meunier J.D., Miche H., Keller C.: Effect of silicon on reducing cadmium toxicity in durum wheat (Triticum turgidum L. cv. Claudio W.) grown in a soil with aged contamination. - J. Hazard. Mater. 209: 326-334, 2012.

Saidi I., Ayouni M., Dhieb A. et al.: Oxidative damages induced by short-term exposure to cadmium in bean plants: Protective role of salicylic acid. - S. Afr. J. Bot. 85: 32-38, 2013.

Sanità di Toppi L., Gremigni P., Pawlik-Skowrońska B. et al.: 
Response to heavy metals in plants: a molecular approach. In: Sanità di Toppi L., Pawlik-Skowrońska B. (ed.): Abiotic Stresses in Plants. Pp. 133-156. Springer, Dordrecht 2003.

Schützendübel A., Schwanz P., Terchmann T. et al.: Cadmium induced changes in antioxidative systems, hydrogen peroxide content, and differentiation in Scots pine roots. - Plant Physiol. 75: 887-898, 2001.

Shi G., Liu C., Cai Q. et al.: Cadmium accumulation and tolerance of two safflower cultivars in relation to photosynthesis and antioxidantive enzymes. - B. Environ. Contam. Tox. 85: 256263, 2010.

Siddiqui M.H., Al-Whaibi M.H., Basalah M.O.: Interactive effect of calcium and gibberellin on nickel tolerance in relation to antioxidant systems in Triticum aestivum L. - Protoplasma 248: 503-511, 2011.

Siddiqui M.H., Al-Whaibi M.H., Sakran A.M. et al.: Calciuminduced amelioration of boron toxicity in radish. - J. Plant Growth Regul. 32: 61-71, 2013.

Siddiqui M.H., Al-Whaibi M.H., Sakran A.M. et al.: Effect of calcium and potassium on antioxidant system of Vicia faba L. under cadmium stress. - Int. J. Mol. Sci. 13: 6604-6619, 2012.

Suzuki N.: Alleviation by calcium of cadmium-induced root growth inhibition in Arabidopsis seedlings. - Plant Biotechnol. 22: 19-25, 2005.

Tan W., Meng Q.W., Brestic M. et al.: Photosynthesis is improved by exogenous calcium in heat-stressed tobacco plants. - J. Plant Physiol. 168: 2063-2071, 2011.

Vaculík M., Pavlovič A., Lux A.: Silicon alleviates cadmium toxicity by enhanced photosynthetic rate and modified bundle sheath's cell chloroplasts ultrastructure in maize. - Ecotox. Environ. Safe. 120: 66-73, 2015.

Xing W., Wang W., Liu G.: Effect of excess iron and copper on physiology of aquatic plant Spirodela polyrrhiza (L.) Schleid. - Environ. Toxicol. 25: 103-112, 2010.

Xu C., Li X., Zhang L.: The effect of calcium chloride on growth, photosynthesis, and antioxidant responses of Zoysia japonica under drought conditions. - PLoS ONE 8: doi: 10.1371/ journal.pone.0068214, 2013.

Xu D., Wang W., Gao T. et al.: Calcium alleviates decreases in photosynthesis under salt stress by enhancing antioxidant metabolism and adjusting solute accumulation in Calligonum mongolicum. - Conserv. Physiol. 5: doi:10.1093/conphys/ cox060, 2017.

Zhang F., Zhang H., Wang G. et al.: Cadmium-induced accumulation of hydrogen peroxide in the leaf apoplast of Phaseolus aureus and Vicia sativa and the roles of different antioxidant enzymes. - J. Hazard. Mater. 168: 76-84, 2009.

Zou P., Li K., Liu S. et al.: Effect of chitooligosaccharides with different degrees of acetylation on wheat seedlings under salt stress. - Carbohyd. Polym. 126: 62-69, 2015.

(C) The authors. This is an open access article distributed under the terms of the Creative Commons BY-NC-ND Licence. 